University of Massachusetts Amherst

ScholarWorks@UMass Amherst

\title{
Narrowed Gaps and Persistent Challenges: Examining Rural- Nonrural Disparities in Postsecondary Outcomes over Time
}

\author{
Ryan Wells \\ University of Massachusetts Amherst \\ Catherine A. Manly \\ University of Massachusetts Amherst \\ Suzan Kommers \\ University of Massachusetts Amherst \\ Ezekiel Kimball \\ University of Massachusetts Amherst
}

Follow this and additional works at: https://scholarworks.umass.edu/cfssr_publishedwork

Part of the Higher Education Commons

\section{Recommended Citation}

Wells, Ryan; Manly, Catherine A.; Kommers, Suzan; and Kimball, Ezekiel, "Narrowed Gaps and Persistent Challenges: Examining Rural-Nonrural Disparities in Postsecondary Outcomes over Time" (2019).

American Journal of Education. 32.

https://doi.org/10.1086/705498

This Article is brought to you for free and open access by the Center for Student Success Research at ScholarWorks@UMass Amherst. It has been accepted for inclusion in Published Work by an authorized administrator of ScholarWorks@UMass Amherst. For more information, please contact scholarworks@library.umass.edu. 


\title{
Narrowed Gaps and Persistent Challenges: Examining Rural-Nonrural Disparities in Postsecondary Outcomes over Time
}

\author{
RYAN S. WELLS, CATHERINE A. MANLY, SUZAN KOMMERS, \\ and EZEKIEL KIMBALL \\ University of Massachusetts Amherst
}

\begin{abstract}
Empirical studies have concluded that rural students experience lower rates of college enrollment and degree completion compared to their nonrural peers, but this literature needs to be expanded and updated for a continually changing context. This article examines the rural-nonrural disparities in students' postsecondary trajectories, influences, and outcomes. By comparing results to past research using similar national data and an identical design, we are able to examine change over time. Results show narrowed gaps from the 1990s into the 2000s, but with rural students still facing persistent challenges and experiencing lower average rates of college enrollment and degree completion.
\end{abstract}

In the aftermath of the 2016 election, there has been a significant national conversation about the relationship among rurality, college education, social class, and politics (e.g., Brown and Fisher 2017; Means 2018; Pappano 2017). Such dicussions have often noted that the educational pathways of rural students differ from those of their nonrural peers (e.g., Barcus and Brunn 2010; Pierson and Hanson 2015; Roscigno et al. 2006). On occassion, discussions of rurality have even taken care to note that variations in educational trajectories stem in part from differences in college-going opportunities in rural areas, which are often related to suppressed postsecondary attendance and completion (e.g., Byun et al. 2012; Koricich et al. 2018; Turley 2009). However, when educators, journalists, scholars, and others use educational research to inform conversations about the multiple and complicated influences of rurality on college going and degree attainment, they find a literature base that is limited in its ability to

Electronically published October 9, 2019

American Journal of Education 126 (November 2019)

(C) 2019 by The University of Chicago. All rights reserved.

0195-6744/2019/12601-0001\$10.00 
explain the college-going behaviors of rural students. In large measure, this stems from the scarcity of high-quality research on rural college going, particularly studies that attempt to ascertain the ongoing accuracy of prior study findings over time as social, economic, and political factors continually shift.

A key study by Byun et al. (2012) explored a complex set of rural influences with data from the National Educational Longitudinal Study of 1988-2000 (NELS: 88-00). This study demonstrated that most of the suppression of postsecondary outcomes for rural students could be explained by their lower average socioeconomic statuses, yet also found support for the notion that some features of rural populations - for example, the strong sense of community — could function as a protective factor in the realization of postsecondary educational aspirations. While valuable, the conclusions from this study are generalizable to a group of high school students who graduated in 1992 and completed college approximately 20 years ago. Much has changed in rural America since then, and social scientists acknowledge that changing political and social contexts influence rural schools and their students' success (Means 2018). Therefore, the ways that economic, community, and demographic factors influence rural college students' trajectories may also differ in a more recent context. While several studies have addressed rural students' college going since that time, providing

Ryan S. WeLLS is director of the Center for Student Success Research and associate professor in the Department of Educational Policy, Research, and Administration at the University of Massachusetts Amherst. His research aims to understand factors that help and hinder postsecondary access and success for marginalized and underresearched groups of students. CATHERINE A. MANLY is a doctoral candidate in the Department of Educational Policy, Research, and Administration at the University of Massachusetts Amherst. Her research aims to improve affordable postsecondary access and success for students underserved by traditional higher education, particularly through the changes possible because of online and educational technologies. SUZAN KOMMERS is a doctoral candidate in the Department of Educational Policy, Research, and Administration at the University of Massachusetts Amherst. Her research focuses on how geographic mobility relates to students' postsecondary success, specifically for underrepresented groups of students. EzEKIEL KIMBALL is an assistant professor in the Department of Educational Policy, Research, and Administration at the University of Massachusetts Amherst. His research examines how postsecondary learning environments shape access and success for minoritized student populations - with a particular interest in the experiences of students with disabilities. 
valuable understanding of the newer context (Koricich et al. 2018; Means et al. 2016), a direct comparison to prior research through replication of past work with newer data would help to understand the way that shifts in American society have shaped rural college going. This knowledge would help researchers and policy makers to understand whether more recently observed trends stem from the fundamental nature of rural communities, broader shifts in the social, political, and economic landscape, or some combination of the two. The purpose of this article, therefore, is to understand how rural-nonrural disparities in students' postsecondary trajectories, influences, and outcomes have changed over time.

We utilize the most recent nationally representative data available that include both college enrollment and college completion. Specifically, we examine twelfth-grade students from 2004 and follow their college enrollment and completion up through 2012. These data allow us to compare our results directly to those of existing research and to examine the stability of past findings and further explore the complex and potentially contradictory predictors of rural educational trajectories. We are guided by the question: How have postsecondary education trajectories for rural and nonrural students changed over time? We examine change between the 1990s (based on NELS data) and the 2000s (based on ELS data). Specifically, we ask the following research questions:

1. How did rural-nonrural disparities in postsecondary enrollment and completion change between the 1990s and 2000s?

2. How did predictors of enrollment and completion for rural and nonrural students (socioeconomic background, family resources, social community resources and academic preparation) change between the 1990s and 2000s?

By addressing these questions, we aim to generate knowledge about the recent status of rural students, the role of rurality in the college-going and completion processes, and how these phenomena have changed over time. For the more than 60 million Americans who live in rural areas (US Census Bureau 2010), such research is vital to understanding the causes and consequences of changing social and educational contexts. Among high school students, many of whom will be considering if and how college fits into their future plans, more than 18\% come from rural areas (Koricich et al. 2018). Results from this research will inform educational policy and practice to close educational opportunity gaps for this vital student population and help to ground reenergized discourses about rurality and education in relation to a variety of social and political phenomena. 


\section{Literature Review: A Changing Context for Rural Educational Pathways}

For the years under consideration for comparison in this study-high school graduates in 1992 compared to high school graduates in 2004 - there has been an increase in college attendance and completion in the United States overall (National Center for Educational Statistics [NCES] 2016). In 1991, 45\% of high school completers enrolled in 2- or 4-year colleges. This went up to $48 \%$ in the year 2000. As more students attended college, more students also completed their bachelor's degrees. Between the academic years 2002-03 and 2012-13, the total number of postsecondary credentials conferred increased at all degree levels: certificates by $49 \%$, associate's degrees by $59 \%$, bachelor's degrees by $36 \%$, master's degrees by $45 \%$, and doctoral degrees by 44\% (NCES 2016). While these numbers show an increase in college attendance and completion in general, the attendance and completion of rural students may not necessarily have followed the overall trends. A report of the US Department of Agriculture showed that even though the percentage of adults with a bachelor's degree overall is growing, the growth was less strong in rural areas, resulting in an increasing rural-urban gap in college completion (Marré 2017). In general, educational attainment in rural areas is highly correlated with measures of regional economic prosperity, poverty, unemployment, and population loss (Marré 2017). During the 1992-2004 time period, rural areas were dealing with complicated and at times contradictory economic, community, and demographic factors, possibly resulting in distinct changes in college enrollment and completion for rural students compared to their urban counterparts.

\section{Economic Resources and Development}

Socioeconomic changes of the late twentieth and early twenty-first centuries have commonly been perceived as not being kind to rural communities (Marcus and Krupnick 2017; Schafft and Jackson 2010). According to this narrative, the family farm-based agriculture upon which rural communities have historically relied has been replaced by industrial farming, which has reduced the already scant employment opportunities in rural communities (Lobao and Meyer 2001; Schafft and Jackson 2010). Limited career prospects led some rural youth to see postsecondary education as a means to escape their home communities (Carr and Kefalas 2010; McGrath et al. 2001).

However, this story is overly simplistic. Not all rural youth aspire to leave their home communities to pursue postsecondary education opportunities, and 
not all of those who do so depart permanently (Barcus and Brunn 2009; Byun et al. 2015; Petrin et al. 2014; Provasnik et al. 2007). Additionally, rural labor markets shifted to become more service-oriented as manufacturing-oriented jobs declined and interest in the intellectual development of rural students grew (Chenoweth and Galliher 2004; Flora and Flora 1990; Johnson 2012). Growth in the marketing of rural areas as recreational spaces also introduced new entrepreneurial opportunities in rural communities (Ilbery 2014). These developments led many rural youth toward a future outside farming (McGrath et al. 2001) and toward jobs requiring postsecondary credentials (Ilbery 2014), creating a greater need for rural youth to get bachelor's degrees. Understanding how rural areas influence college going is therefore complicated and must account for multiple factors that are often in tension. One of the biggest differences between the time periods under study is the economic recession of 20072009, which had dire effects economically (Grusky et al. 2011) and also had a differential effect on rural communities, potentially influencing rural students' efforts toward degree completion. Falling incomes and rising unemployment rates reduced economic well-being and stability in the United States (Long 2014) and resulted in many rural families having to deal with chronic economic insecurity (Sherman and Sage 2011). The financial crisis impacted rural communities' employment, wages, and family finances - all of which may have altered both student motivations to complete their degree and parental ability to pay for it (Shapiro et al. 2015; Sherman and Sage 2011). While socioeconomic status is often discussed in an urban context, poverty is also related to social processes and structures in rural areas, including education (Koricich et al. 2018). In our study, even rural students who enrolled immediately after high school in 2004 likely would have had to contend with effects of the recession prior to completion of their degree. For those who delayed college entry, it likely also affected their college access and choice. One study occurring during the recession did not show a clear relationship between the recession and students' college plans (Petrin et al. 2014). However, the authors noted that the data collection occurred at a time when the full impact of the recession had not yet filtered down to rural communities, suggesting some uncertainty of the influence of the recession on rural communities during the years relevant for the present study.

The recession also had a negative effect on postsecondary institutions through budget cuts (Long 2014). Institutions experienced decreasing resources to support financially struggling students. Moreover, institutions implemented tuition increases to counterbalance reductions in government support (Long 2014). For rural families who, on average, already had lower socioeconomic statuses (Byun et al. 2012), eventual increases in college tuition may have disproportionately impacted them in their efforts to support students completing degrees. At the 
same time however, if students saw their rural home communities being disproportionately hit by the crisis, they may also have realized the importance of completing their bachelor's degree even more. In short, there has been no clear consensus on how the financial crisis may have impacted the college going of rural students, but the recession was a clear and important difference to note between the two time periods being compared in this study.

\section{Community Resources}

Rural students often have a relatively tight and socially interconnected community among family, schools, and religious institutions (Crockett et al. 2000). Rural students have been shown to be more likely to have residential stability, engage in a religious community, and have parents who know their friends' parents, all of which are associated with increased achievement in school (Byun et al. 2012; Israel et al. 2001). Overall, students growing up in rural areas may have a stronger connection to their home community than their nonrural peers (Howley 2006; McGrath et al. 2001; Petrin et al. 2011).

While the attachment to one's home community may be a limiting factor for rural students' college attendance (Turley 2009), such attachment has also been shown to be positively related to academic achievement and college completion for rural students through community-related resources (Byun et al. 2012; Petrin et al. 2014). A strong connection to one's home community may make rural students aspire to remain a part of that community even when engaging in postsecondary education (Petrin et al. 2011). Place attachment may also increase the desire to attend college close to home, which has often been among the most important factors that US high school students consider when choosing a college, especially students with low socioeconomic status (Holloman and Nolen 2008; Turley 2009). However, given recent evidence that several rural areas may be characterized as "education deserts" with no more than one community college in a reasonable commuting distance (Hillman 2016), the desire to attend college close to home may diminish overall enrollment rates for rural students who may be forced to move away for such access.

From another perspective, technology advancements from the 1990s to the 2000s may have made it easier for rural students to travel and stay connected to their home communities even when at a distance. These technological developments allowed rural students to be more easily in touch with their rural home, potentially lessening the loss of place, which may have otherwise discouraged rural students from moving out of a rural area to attend college (Barcus and Brunn 2009; Petrin et al. 2011). Moreover, increased online communication potentially allowed rural students to benefit more from their social community resources in their home communities even when in college. Online technology 
may have also allowed rural students to enroll in college online, without physically leaving their community. However, this likelihood is tempered by the fact that rural areas have been the least well served by the broadband technology necessary to do so (Rosenboom and Blagg 2018).

\section{Demographics}

Census data indicate that during the past few decades, significant demographic changes have been reshaping rural America (Johnson 2012). Between the early 1900 s and the 1970s, nonmetropolitan areas experienced widespread outmigration. From the 1990 s to the 2000 s, the rural population actually grew slightly. However, the increase in population in rural areas was not primarily due to natural increase through children being born. In the 1990s, two-thirds of the nonmetropolitan population gain was due to migration, some of which was connected to retirement and recreation (Johnson 2012). Many older people have chosen to live in small communities outside of urban areas (Tarmann 2003). The fact that the population growth was partially rooted in an older demographic may be expected to result in little change to the college-going populations within rural communities.

In addition to the aging nature of the rural population, populations of color have had a growing impact (Johnson 2012). People of color should be considered in modern rural contexts, but they have often been overlooked (Means et al. 2016). In particular, while Hispanics accounted for only $4 \%$ of the nonmetropolitan population in 1990, they were responsible for $25 \%$ of the growth in this population in subsequent years (Tarmann 2003). Much of this growth was due to immigration, but was also related to this group's higher proportion of adults of childbearing age. The increase of Hispanics in rural areas from the 1990 s to the 2000s indicated an increase in youth of high school age, but these students may additionally experience challenges based on language, immigration status, or racial and ethnic discrimination.

Overall, rural areas changed from the 1990s and 2000s on many levels, likely impacting the rural-nonrural disparities in college going and completion. While the literature consistently indicates that economic, community, and demographic factors are important, it remains unclear precisely how changes in these factors would have influenced rural students' college going and completion over the time span being considered. The changes in economic resources and development indicate that college degrees became more necessary in rural areas at a time when technological developments made enrollment and completion potentially more feasible. Simultaneously, literature indicates that the financial situation of rural areas was not improving and overlapped with the recession, making it harder for rural students to find the resources to attend 
college and complete their degree. During this time period, the rural population increasingly consisted of retired people and a Hispanic population, but it has been unclear how such changes impacted the college-going population. The complicated developments that impacted rural areas for the years under study preclude the development of a clear hypothesis about the changes over time. However, it is clear that there is a need to conduct research with the explicit goal of examining changing influences over time to examine the impact of these changing contexts and the resultant impact on postsecondary disparities between rural and nonrural students.

\section{Conceptual Framework}

The logic of replication in social science research (Firebaugh 2008) and the prior findings of Byun and colleagues (2012) provide the conceptual framework for our study. This framework is supported by our literature review, which suggests that changing societal influences on the educational trajectories of rural youth require further investigation. This reinforces the aims of our research questions, which explicitly inquire about changes in educational outcomes over time for rural students, as well as the ways that previously studied predictors of college enrollment and completion may have changed in their influence. In other words, this article is framed as a study of societal change, drawing on the logic of replication and seeking to update prior findings.

To meaningfully frame this inquiry as a study of social change, we rely on data and methods that are suitable for the task. According to the sixth of Firebaugh's (2008) seven rules, researchers should use "repeated cross-section data to study social change" (172). Therefore, we selected ELS data for our analysis. In addition to being useable as a standalone data set, ELS is designed as a repeated cross section when used in combination with other national data collections occurring approximately once per decade. Therefore, we are able to directly compare our results from the 2000s using ELS to those of Byun et al. (2012), who used NELS data primarily from the 1990s.

Although there are trade-offs to decisions regarding such replication attempts, we leverage Firebaugh's (2008) fourth rule and conduct "identical analyses of parallel datasets" (105) such that our comparisons are most likely to reveal changes due to contextual differences over time. Doing so mitigates the possibility that apparent findings of change over time stem from variable operationalization or statistical choices rather than changing societal trends. Although there are some minor differences in the survey items used to collect data between the two data sets (detailed below), nearly all of the variables used were collected from a similar national sample with identical survey items. By comparing results from NELS and ELS, we are able to exploit the nature of 
repeated cross-sectional data for studying social change (Firebaugh 2008), which is our aim in relation to rural students from the 1990s to the 2000s.

\section{Data and Methods}

We utilized US National Center for Education Statistics (NCES) data from the Education Longitudinal Study (ELS: 2002-12). ELS followed a nationally representative cohort of tenth-grade students in 2002 throughout their high school and college years, with a fourth and final data collection wave in 2012, 8 years after their expected high school graduation (Ingels et al. 2014). These data are nationally generalizable and are the most recent national data available to study college degree completion, which also include the precollege background variables necessary for our study.

\section{Variables}

The selection of variables was determined by our desire to be as consistent as possible with the variables and operational definitions used by Byun and colleagues (2012) to better isolate the source of any differences over time that we find. The dependent variables, therefore, were: (a) college enrollment and (b) bachelor's degree attainment. Both studies had analytic samples of twelfthgrade students and an 8-year span of time between graduating high school and collection of the final wave of data.

Independent variables used by Byun et al. (2012) were grouped into the following categories: socioeconomic background, family composition and social resources, community social resources, and academic background in high school (with controls for race, gender, and region also used). Most of the variables from ELS are operationalized the same way they were in NELS. However, a NELS variable for curriculum intensity in high school did not exist in ELS, so we included variables for academic concentrator and highest math course taken to similarly reflect the quality and quantity of the high school curriculum. While these two variables aim to jointly serve the same purpose in our models, the differences preclude us from directly comparing these variables over time.

Social community resources, defined as "a supportive community that may offer additional resources" (Byun et al. 2012, 415) was operationalized with three variables - communication with parents of a child's friends; the extent to which a parent knows the parents of their child's friends; and the frequency of attendance at religious services. Whereas all of these variables existed in ELS similarly to NELS, the response items on the surveys were slightly different in terms of the number and scale of the response options. However, we recoded 
them to be comparable and therefore continue to make comparisons of these variables between the 1990s and the 2000s. ${ }^{1}$

NCES provided indicators of the location of schools that students attended, which allowed us to create indicators of rural, suburban, and urban status, similar to Byun et al. (2012). However, it is important to note that the urban, suburban, and rural variables provided in ELS were not equivalent to NELS due to a more granular set of categories being used in ELS to define rural schools. This resulted in some of the locations that were considered rural in NELS to be considered nonrural in ELS. To correct for this, we did not use the NCES-created variables for urban, rural, and suburban, but instead created our own variables from the locale codes provided, which were identical in operational definition to those in NELS used by Byun et al. (2012). (For more detail about these rurality variable differences and implications, see Manly et al. 2019.) This approach cannot simultaneously overcome the challenge of reclassification of metropolitan (and therefore also rural) areas (Johnson 2012), but it is the best means available to provide consistent and meaningful comparison over time with these data.

\section{Missing Data}

Without addressing missing data, approximately $31 \%$ of the cases would have been dropped. We examined patterns of missing data and the appropriateness of imputations (van Buuren 2012), concluding that assuming data were missing at random was reasonable (Allison 2002; Manly and Wells 2015). Given this, we used multiple imputation to handle the missing data, which was also consistent with the procedures used by Byun et al. (2012). Based on guidance provided by White, Royston, and Wood (2011) we created 100 imputations using the mi impute chained command in Stata v.13. All variables were included in the imputation models, as well as the primary sampling unit, strata variables, and the appropriate weights for each decade's data set (Heeringa et al. 2010). We then used Rubin's (1987) pooling rules to combine the statistical results across the imputed data sets. Results using both list-wise deletion and multiple imputation (MI) are substantively similar for rural students, so imputed results are presented. ${ }^{2}$

\section{Statistical Analyses}

To address our research questions, we first utilized descriptive statistics to examine differences between college enrollment and completion for rural, suburban, and urban high school students. We provided mean values and standard 
errors on all variables for all students. We examined variables for rural, suburban, and urban students separately, to begin to understand how the subsamples differed from one another. To make statistical comparisons of the mean values for suburban and urban students in relation to rural students, we conducted a series of bivariate multinomial logistic regressions; these analyses provided a comparison of whether the variable was significantly different for urban or suburban students in relation to rural students.

Subsequently, we used binary logistic regression to examine the outcome of college enrollment. For this and subsequent steps, we continued to base our model specifications on that of Byun et al. (2012) so that a comparison of our findings to theirs provides the most robust understanding of changes over time. Therefore, we first included variables to examine how urbanicity/rurality predicted enrollment (with controls for gender, race, and geographic region of the country already included). Subsequently, we included socioeconomic factors, family and social resources, community social resources, and academic preparation variables. These models control for a variety of key influences on enrollment in response to our second research question and provide an understanding of which predictors are most important overall. Again, emulating Byun et al. (2012), we analyzed the full model with all predictors separately by rural, suburban, and urban location, allowing us to see which predictors were differentially important for enrollment by location type.

Next, we followed the same procedures, but for the outcome of college degree attainment. For this analysis, we used multinomial logistic regression, which is the appropriate technique for the multicategorical nature of the dependent variable (Long 1997): (a) no degree completion, (b) associate degree or certificate completion, or (c) bachelor's degree completion or higher, all relative to (d) no college. We again introduced the independent variables as described above.

We then statistically compared our descriptive and regression results to those obtained by Byun et al. (2012), who used data from a decade earlier. To make this comparison for the descriptive results, we utilized multiple $t$-tests. To make the comparison of regression results, we relied on a technique from Clogg et al. (1995) that is appropriate for large data sets such as these: the difference in the coefficients divided by the square root of the sum of squares of the standard errors $\left(\left[b_{2}-b_{1}\right] / J\left[\left(s e_{2}^{2}+s e_{1}^{2}\right]\right) .^{3}\right.$ Although the assumptions underlying this technique may be partially violated and lead to an increased likelihood for Type I error (Allison 1995), this technique has been used for similar educational research in the past (Domina et al. 2011) and we interpret the results conservatively so as not to overstate differences that may be found. To test the sensitivity of this comparison to the method employed, and following Domina and colleagues (2011), we also used NELS data identically to how they were used by Byun et al. (2012) and then pooled NELS and ELS data and reran all regression 
analyses. By including an interaction term between the cohort (NELS vs. ELS) and the rurality/urbanicity variables, we could determine if the association between rurality and the outcomes was different in the ELS data than in the NELS data.

Finally, using results from the full regression model, we calculated predicted probabilities of enrollment and completion for a rural student, a suburban student, and an urban student (Long and Freese 2014, 278). These probabilities were calculated by varying only the urbanicity/rurality variables while holding all other values at their within-group means. This provided a more intuitive metric and visual presentation by which to understand the salience of rurality on outcomes. Because the ELS data collection followed a complex sampling strategy, all analyses account for this design using Stata's soy command (Heeringa et al. 2010). This technique also properly weights the analyses per NCES standards, to account for oversampling and some nonresponse.

These data and methods have some limitations. As stated, we purposely used models that were as identical as possible to those from Byun and colleagues (2012) in order to make valid analyses of change over time. In doing so, we are not considering other models and therefore may be subject to issues of omitted variables, or, conversely, overcontrol bias. As also noted, given the purpose of our study as understanding change over time, we used an operational definition for rurality consistent with the prior research with NELS data.

Results

\section{Descriptive Results}

Rural twelfth-grade students from 2004 enrolled in college at rates lower than their suburban and urban peers. As shown in table 1, 86\% of rural students enrolled in college in the subsequent 8 years as compared with $90 \%$ and $89 \%$ of suburban and urban students, respectively. Despite lagging behind their peers, the gap between rural and nonrural students narrowed over time, as is evident from comparing these results to those for high school students in 1992 (table 2). For all students, the rate of college enrollment was more than 8 percentage points higher in the 2000s compared to the 1990s. However, this rate of increase appears to be driven primarily by rural students; their rate of college enrollment increased by more than 12 percentage points, compared to approximately 8 and 5 percentage points for suburban and urban students, respectively.

When examining degree attainment, rural students had lower rates of bachelor's degree attainment relative to suburban students. Among rural twelfthgraders, $34 \%$ had completed at least a bachelor's degree by 2012 , compared to 
$41 \%$ of suburban students (table 1). This was similar to the results from a decade earlier with NELS data, but the gaps were diminished. In the 1990s, there was a 10 percentage-point gap in degree attainment between rural and suburban students and a 13 percentage-point gap between rural and urban students; these gaps were reduced to 7 and 4 percentage points, respectively, in the 2000s. This relatively large change was primarily the result of higher bachelor's attainment rates for rural students in the 2000s compared to the 1990s and slightly lower rates for urban students, with little change for suburban students (table 2).

Table 2 shows how other factors have changed over time, and how such changes differed for rural and nonrural student populations. There was an increase for all students in the levels of parental educational attainment, but particularly for rural students. The proportion of rural students who had a parent with at least a bachelor's degree increased by 26 percentage points. Looked at another way, a smaller proportion of all twelfth-graders in the 2000s relative to the 1990s were potential first-generation college students, but this phenomenon appears particularly salient for rural students.

In looking at the category of social community resources, it appears parents in 2004 communicated more with parents of their children's friends and knew those parents better compared to their 1992 counterparts. Attendance at religious services decreased for all students, but particularly for those from rural areas. While the question for religious service attendance was asked slightly differently in ELS and NELS (i.e., a general versus specific frequency), meaning that the specific value of this decrease may be questioned, the relatively larger decrease for rural students than others is still worthy of note.

Interestingly, while academic preparation increased for all students over the decade, it increased relatively more for rural students than for others. The GPA for rural students went up by about 0.22 points, while the mean increase for all students was 0.12 points. Scores on a standardized test administered by NCES also increased for rural students, whereas the average scores actually decreased for suburban and urban students. However, the test was different in 2004 compared to 1992, so the estimated changes are less salient than the relative differences between geographic subpopulations. ${ }^{4}$

\section{Regression Results}

Enrollment.-When variables representing suburban and urban locations (relative to rural) are included without other controls in a logistic regression model, they confirm that both suburban and urban students are more likely than rural students to enroll in college (see table 3). Specifically, suburban students had odds of enrollment that were nearly 1.5 times larger than rural students' odds, and urban students' odds were larger by almost the same factor. Similar to Byun 
TABLE 1

Means and Standard Errors of the Estimates, for All Variables

\begin{tabular}{|c|c|c|c|c|c|c|c|c|}
\hline \multirow[b]{2}{*}{ VARIABLE } & \multicolumn{2}{|c|}{$\begin{array}{c}\text { ALL } \\
(\mathcal{N}=10,620)\end{array}$} & \multicolumn{2}{|c|}{$\begin{array}{c}\text { RURAL } \\
(\mathcal{N}=3,240)\end{array}$} & \multicolumn{2}{|c|}{$\begin{array}{l}\text { SUBURBAN } \\
(\mathcal{N}=3,960)\end{array}$} & \multicolumn{2}{|c|}{$\begin{array}{c}\text { URBAN } \\
(\mathcal{N}=3,400)\end{array}$} \\
\hline & Mean & $\mathrm{SE}$ & Mean & $\mathrm{SE}$ & Mean & $\mathrm{SE}$ & Mean & SE \\
\hline \multicolumn{9}{|l|}{ Dependent variables: } \\
\hline College enrollment & .88 & $(.00)$ & .86 & $(.01)$ & $.90 * *$ & $(.01)$ & $.89 *$ & $(.01)$ \\
\hline \multicolumn{9}{|l|}{$\begin{array}{l}\text { College degree } \\
\text { attainment: }\end{array}$} \\
\hline \multicolumn{9}{|l|}{ No college } \\
\hline enrollment & .12 & $(.00)$ & .14 & $(.01)$ & $.10 * *$ & $(.01)$ & $.11^{*}$ & $(.01)$ \\
\hline Associate's degree & .19 & $(.00)$ & .20 & $(.01)$ & .19 & $(.01)$ & $.18^{+}$ & $(.01)$ \\
\hline BA or higher & .38 & $(.01)$ & .34 & $(.01)$ & $.41 * *$ & $(.01)$ & .38 & $(.01)$ \\
\hline \multicolumn{9}{|l|}{ No college degree } \\
\hline attainment & .32 & $(.01)$ & .32 & $(.01)$ & .30 & $(.01)$ & .34 & $(.01)$ \\
\hline \multicolumn{9}{|l|}{ Explanatory variables: } \\
\hline \multicolumn{9}{|l|}{ Rurality: } \\
\hline Rural & .28 & $(.01)$ & $\ldots$ & $\ldots$ & $\ldots$ & $\ldots$ & $\ldots$ & $\ldots$ \\
\hline Suburban & .39 & $(.01)$ & $\ldots$ & $\ldots$ & $\ldots$ & $\ldots$ & $\ldots$ & $\ldots$ \\
\hline Urban & .33 & $(.01)$ & $\ldots$ & $\ldots$ & $\ldots$ & $\ldots$ & $\ldots$ & $\ldots$ \\
\hline \multicolumn{9}{|l|}{$\begin{array}{l}\text { Socioeconomic } \\
\text { background: }\end{array}$} \\
\hline \multicolumn{9}{|l|}{$\begin{array}{c}\text { Parental educational } \\
\text { attainment: }\end{array}$} \\
\hline \multicolumn{9}{|l|}{ High school grad } \\
\hline Some college & .22 & $(.01)$ & .25 & $(.01)$ & .22 & $(.01)$ & $.20^{* *}$ & $(.01)$ \\
\hline BA or higher & .52 & $(.01)$ & .46 & $(.01)$ & $.56^{* *}$ & $(.01)$ & $.54^{* *}$ & $(.02)$ \\
\hline \multicolumn{9}{|l|}{ Family income: } \\
\hline$\$ 25,000$ or less & .19 & $(.01)$ & .18 & $(.01)$ & .16 & $(.01)$ & $.23^{* *}$ & $(.01)$ \\
\hline$\$ 25,001$ to & & & & & & & & \\
\hline$\$ 50,000$ & .31 & $(.01)$ & .35 & $(.01)$ & $.28 * *$ & $(.01)$ & $.31^{+}$ & $(.01)$ \\
\hline$\$ 50,001$ or more & .50 & $(.01)$ & .47 & $(.01)$ & $.56 * *$ & $(.01)$ & .45 & $(.01)$ \\
\hline \multicolumn{9}{|l|}{$\begin{array}{c}\text { Family composition } \\
\text { and social } \\
\text { resources: }\end{array}$} \\
\hline \multicolumn{9}{|l|}{ Two-parent } \\
\hline $\begin{array}{l}\text { tamily } \\
\text { Number of }\end{array}$ & .77 & $(.01)$ & .80 & $(.01)$ & .19 & & & $(.01)$ \\
\hline siblings & 1.44 & $(.02)$ & 1.36 & $(.02)$ & $1.44^{+}$ & $(.03)$ & $1.53^{* * *}$ & $(.04)$ \\
\hline $\begin{array}{c}\text { Parental educational } \\
\text { expectations: }\end{array}$ & & & & & & & & \\
\hline $\begin{array}{l}\text { High school grad } \\
\text { or less }\end{array}$ & .06 & $(.00)$ & .07 & $(.01)$ & $.06^{+}$ & $(.01)$ & $.05^{+}$ & $(.01)$ \\
\hline Associate's degree & .17 & $(.01)$ & .22 & $(.01)$ & $.15^{* *}$ & $(.01)$ & $.13^{* *}$ & $(.01)$ \\
\hline BA or higher & .77 & $(.01)$ & .71 & $(.01)$ & $.79 * *$ & $(.01)$ & $.82^{* * *}$ & $(.01)$ \\
\hline $\begin{array}{l}\text { Parents discuss with } \\
\text { child }\end{array}$ & 2.23 & $(.01)$ & 2.23 & $(.01)$ & 2.22 & $(.01)$ & 2.24 & $(.01)$ \\
\hline
\end{tabular}




\begin{tabular}{|c|c|c|c|c|c|c|c|c|}
\hline \multirow[b]{2}{*}{ VARIABLE } & \multicolumn{2}{|c|}{$\begin{array}{c}\text { ALL } \\
(\mathcal{N}=10,620) \\
\end{array}$} & \multicolumn{2}{|c|}{$\begin{array}{c}\text { RURAL } \\
(\mathcal{N}=3,240) \\
\end{array}$} & \multicolumn{2}{|c|}{$\begin{array}{c}\text { SUBURBAN } \\
(\mathcal{N}=3,960)\end{array}$} & \multicolumn{2}{|c|}{$\begin{array}{c}\text { URBAN } \\
(\mathcal{N}=3,400)\end{array}$} \\
\hline & Mean & SE & Mean & $\mathrm{SE}$ & Mean & SE & Mean & SE \\
\hline $\begin{array}{r}\text { Community } \\
\text { resou }\end{array}$ & & & & & & & & \\
\hline $\begin{array}{r}\text { Comm. w } \\
\text { frien } \\
\text { Parents kl }\end{array}$ & 1.88 & $(.01)$ & 1.91 & $(.02)$ & 1.87 & $(.02)$ & $1.84^{* *}$ & $(.02)$ \\
\hline & 2.42 & $(.01)$ & 2.53 & $(.02)$ & $2.41^{* * *}$ & $(.02)$ & $2.32^{* * *}$ & (.03) \\
\hline $\begin{array}{r}\text { churc } \\
\text { Academic pr } \\
\text { in hig }\end{array}$ & 3.03 & $(.02)$ & 3.09 & $(.03)$ & $2.97 * *$ & $(.03)$ & 3.04 & (.03) \\
\hline $\begin{array}{l}\text { GPA } \\
\text { Standardized test }\end{array}$ & 2.82 & $(.01)$ & 2.91 & $(.02)$ & $2.83^{* * *}$ & $(.02)$ & $2.70^{* * *}$ & (.03) \\
\hline Acade & 51.51 & $(.19)$ & 51.92 & $(.26)$ & 52.25 & $(.32)$ & $49.97^{* * * *}$ & $(.41)$ \\
\hline 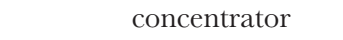 & .28 & $(.01)$ & .26 & $(.01)$ & $.30 *$ & $(.01)$ & .29 & $(.0$ \\
\hline Highe & 5.59 & $(.03)$ & 5.45 & $(.04)$ & $5.70^{* * *}$ & $(.05)$ & $5.58 *$ & $(.0$ \\
\hline Contr & & & & & & & & \\
\hline $\begin{array}{l}\text { Female } \\
\text { Race/ethnicity: }\end{array}$ & .51 & $(.01)$ & .52 & $(.01)$ & .51 & $(.01)$ & .51 & $(.01$ \\
\hline & .05 & $(.00)$ & .02 & $(.00)$ & $.05^{* * * *}$ & $(.01)$ & $.07 * * * *$ & $(.01)$ \\
\hline & .16 & $(.01)$ & .07 & $(.01)$ & $.16^{* * * *}$ & $(.01)$ & $.25^{* * * *}$ & $(.0$ \\
\hline Bla & .14 & $(.01)$ & .09 & $(.01)$ & .11 & $(.01)$ & $.24 * * *$ & $(.02)$ \\
\hline White & .66 & $(.01)$ & .82 & $(.01)$ & $.68 * * *$ & $(.02)$ & $.44^{* * * *}$ & $(.0$ \\
\hline Regio & & & & & & & & \\
\hline $\mathrm{N}$ & .19 & $(.01)$ & .14 & $(.02)$ & $.25 * * *$ & $(.02)$ & .16 & $(.0$ \\
\hline & .25 & $(.01)$ & .26 & $(.02)$ & .26 & $(.02)$ & .20 & $(.0$ \\
\hline & .34 & $(.01)$ & .43 & $(.02)$ & $.25^{* * * *}$ & $(.02)$ & $.37 *$ & $(.0$ \\
\hline West & .22 & $(.01)$ & .17 & $(.02)$ & $.23^{*}$ & $(.02)$ & $.27 * * *$ & $(.0$ \\
\hline
\end{tabular}

NoTE.-All reported sample sizes are rounded to the nearest 10 in accordance with NCES restricted data license.

Significant differences from rural areas marked.

$* p<.05$ (two-tailed tests).

$* * *<.01$.

$* * * *<<.001$.

et al.'s (2012) findings using NELS data, these differences were not present (below our threshold for statistical significance) when other variables were added to the model. ${ }^{5}$ Not surprisingly, students with higher levels of parental educational attainment and family income were more likely to enroll. Given that rural students had lower rates of parental bachelor's degree attainment and lower family 
TABLE 2

Change in Mean Value (ELS - NELS) on Key Variables Between 1992 and 2004, for the Full Sample and by Urbanicity

\begin{tabular}{|c|c|c|c|c|}
\hline Variable & All & Rural & Suburban & Urban \\
\hline \multicolumn{5}{|l|}{ Dependent variables: } \\
\hline College enrollment & $.084 * * *$ & $.121 * * *$ & $.08 * * *$ & $.051 * * *$ \\
\hline \multicolumn{5}{|l|}{ College degree attainment: } \\
\hline No college enrollment & $-.084 * * *$ & $-.121^{* * *}$ & $-.08 * * *$ & $-.051 * * *$ \\
\hline Associate's degree & $.091 * * *$ & $.083^{* * * *}$ & $.091 * * *$ & $.087 * * *$ \\
\hline BA or higher & -.002 & $.042^{* *}$ & .01 & $-.055^{* *}$ \\
\hline No college degree attainment & -.004 & -.004 & -.021 & .018 \\
\hline \multicolumn{5}{|l|}{ Explanatory variables: } \\
\hline \multicolumn{5}{|l|}{ Socioeconomic background: } \\
\hline \multicolumn{5}{|l|}{ Parental educational attainment: } \\
\hline High school graduation or less & $-.048 * * *$ & $-.078^{* * *}$ & $-.043^{* *}$ & -.006 \\
\hline Some college & $-.176^{* * *}$ & $-.192^{* * *}$ & $-.18 * * *$ & $-.169 * * *$ \\
\hline BA or higher & $.224^{* * * *}$ & $.259 * * *$ & $.223^{* * *}$ & $.184^{* * *}$ \\
\hline \multicolumn{5}{|l|}{ Family income: } \\
\hline$\$ 25,000$ or less & $-.123^{* * * *}$ & $-.197 * * *$ & $-.092 * * *$ & $-.087 * * *$ \\
\hline$\$ 25,001$ to $\$ 50,000$ & $-.039 * * *$ & $-.041 * *$ & $-.073^{* * *}$ & .005 \\
\hline$\$ 50,001$ or more & $.162^{* * * *}$ & $.238 * * *$ & $.165 * * *$ & $.082^{* * *}$ \\
\hline \multicolumn{5}{|l|}{$\begin{array}{l}\text { Family composition and social } \\
\text { resources: }\end{array}$} \\
\hline Two-parent family & $.114 * * *$ & $.172 * * * *$ & $.113 * * *$ & $.063 * * *$ \\
\hline Number of siblings & $-2.819^{* * * *}$ & $-2.808^{* * *}$ & $-2.835^{* * *}$ & $-2.822^{* * *}$ \\
\hline \multicolumn{5}{|c|}{ Parental educational expectations: } \\
\hline High school graduation or less & $.02 * * *$ & $.012^{*}$ & $.015^{* *}$ & $.021 * * *$ \\
\hline Associate's degree & $-.012^{*}$ & -.011 & -.007 & 0 \\
\hline BA or higher & -.008 & .009 & -.009 & -.021 \\
\hline Parents discuss with child & $-.302 * * *$ & $-.273^{* * *}$ & $-.328 * * *$ & $-.301 * * *$ \\
\hline \multicolumn{5}{|l|}{ Community social resources: } \\
\hline Comm. with child's friend's parent & $.115^{* * *}$ & .03 & $.162^{* * *}$ & $.138 * * *$ \\
\hline Parents & $.175^{* * * *}$ & $.126^{* * *}$ & $.213^{* * *}$ & $.162^{* * * *}$ \\
\hline Student attends church & $-.291 * * *$ & $-.345^{* * *}$ & $-.236^{* * *}$ & $-.311^{* * *}$ \\
\hline \multicolumn{5}{|c|}{ Academic preparation in high school: } \\
\hline GPA & $.121^{* * *}$ & $.223^{* * *}$ & $.138 * * *$ & -.01 \\
\hline Standardized test scores & $-1.999 * * *$ & $2.361 * * *$ & $-2.765 * * *$ & $-5.877 * * *$ \\
\hline Academic concentrator & $-2.756^{* * *}$ & $-2.511 * * *$ & $-2.791 * * *$ & $-2.978^{* * *}$ \\
\hline Highest math course & $2.547 * * *$ & $2.68^{* * *}$ & $2.612 * * *$ & $2.314^{* * *}$ \\
\hline \multicolumn{5}{|l|}{ Controls: } \\
\hline Female & -.005 & -.014 & .004 & -.005 \\
\hline \multicolumn{5}{|l|}{ Race/ethnicity: } \\
\hline Asian & $-.033^{* * *}$ & $-.011^{* * *}$ & $-.039 * * *$ & $-.036^{* *}$ \\
\hline Hispanic & $.037^{* * *}$ & -.018 & $.063^{* * *}$ & .039 \\
\hline Black & $.049 * * *$ & -.003 & $.052 * * *$ & $.11 * * *$ \\
\hline White & $-.053 * * *$ & .022 & $-.075^{* * *}$ & $-.113^{* * * *}$ \\
\hline
\end{tabular}


Wells et al.

TABLE 2 (Continued)

\begin{tabular}{cccrr}
\hline Variable & All & Rural & Suburban & Urban \\
\hline Region: & & & & \\
Northeast & .01 & .003 & .014 & -.004 \\
Midwest & $-.033^{* * * *}$ & $-.056^{*}$ & -.036 & -.016 \\
South & .012 & .036 & -.001 & -.007 \\
West & $.021^{*}$ & .026 & .023 & .027 \\
\hline$* p<.05$. & & & & \\
$* * p<.01$. & & & & \\
$* * * p<.001$. & & & &
\end{tabular}

income levels (see table 1), this explains most of the college enrollment gaps. Particularly large increases in odds of enrollment were also predicted by higher parental expectations and better academic preparation. In terms of social community resources, students who more regularly attended religious services were more likely to attend college than those who attended services less often. The significant factors in the final model are very similar to those using NELS data (results of statistical comparison between NELS and ELS regression coefficients available upon request). ${ }^{6}$

When rural, suburban, and urban students were considered in separate regression models to understand how predictors of college enrollment may have been unique, both similarities and differences emerged between the 1990s results and ours. ${ }^{7}$ Several of the strongest predictors were similarly significant, both statistically and substantively. One of the largest predictors for each group was whether a parent expected the child to attain at least a bachelor's degree. Another family-related variable - parent-child discussion - was also strong across all groups. Finally, a higher GPA strongly predicted higher odds of college enrollment for all groups.

There were also differences, however. First, using ELS data, parental educational attainment had the greatest effect $\operatorname{size}^{8}$ and statistical significance for the subsample of suburban students, with smaller associations between parental education and college enrollment for rural and urban students. Whereas a decade earlier the largest effect size for parental education predicting college enrollment was for rural students, using ELS data showed an effect and level of statistical significance that was smaller for rural students relative to suburban students.

A similar trend held true for a key component of social community resources. Whereas attending religious services more often was predictive of college enrollment overall in the 2000s (table 3), it was only marginally statistically significant for rural and suburban students separately (table S2). NELS data from the 1990s showed that rural students had the highest positive association 
TABLE 3

Predictors of College Enrollment: Logistic Regression Analyses, Odds Ratios Reported

\begin{tabular}{|c|c|c|}
\hline Variables & Model 1 & Model 2 \\
\hline \multicolumn{3}{|l|}{ Rurality: } \\
\hline Suburban & $\begin{array}{l}1.480 * * * \\
(.170)\end{array}$ & $\begin{array}{l}1.074 \\
(.143)\end{array}$ \\
\hline Urban & $\begin{array}{l}1.471^{* * *} \\
(.148)\end{array}$ & $\begin{array}{l}1.143 \\
(.125)\end{array}$ \\
\hline \multicolumn{3}{|l|}{ Socioeconomic background: } \\
\hline \multicolumn{3}{|l|}{ Parental educational attainment: } \\
\hline Some college & & $\begin{array}{l}1.220 \\
(.137)\end{array}$ \\
\hline BA or higher & & $\begin{array}{l}1.535 * * * \\
(.166)\end{array}$ \\
\hline \multicolumn{3}{|l|}{ Family income ( $\$ 25,000$ or less omitted): } \\
\hline$\$ 25,001$ to $\$ 50,000$ & & $\begin{array}{l}1.220 \\
(.144)\end{array}$ \\
\hline$\$ 50,001$ or more & & $\begin{array}{l}1.583^{* *} \\
(.228)\end{array}$ \\
\hline \multicolumn{3}{|l|}{ Family composition and social resources: } \\
\hline Two-parent family & & $\begin{array}{l}.927 \\
(.103)\end{array}$ \\
\hline Number of siblings & & $\begin{array}{l}.969 \\
(.040)\end{array}$ \\
\hline \multicolumn{3}{|l|}{ Parental education expectations: } \\
\hline Associate's degree & & $\begin{array}{l}1.791^{* * *} \\
(.294)\end{array}$ \\
\hline BA or higher & & $\begin{array}{l}3.132^{* * * *} \\
(.521)\end{array}$ \\
\hline Parents discuss with child & & $\begin{array}{l}2.151 * * * \\
(.202)\end{array}$ \\
\hline \multicolumn{3}{|l|}{ Community social resources: } \\
\hline Comm. with child's friend's parent & & $\begin{array}{l}1.129 \\
(.093)\end{array}$ \\
\hline Parents know child's friend's parent & & $\begin{array}{l}.872^{*} \\
(.061)\end{array}$ \\
\hline Student attends religious services & & $\begin{array}{l}1.153^{* *} \\
(.053)\end{array}$ \\
\hline \multicolumn{3}{|l|}{ Academic preparation in high school: } \\
\hline GPA & & $\begin{array}{l}1.822 * * * \\
(.163)\end{array}$ \\
\hline Standardized test scores & & $\begin{array}{l}1.027 * * * \\
(.007)\end{array}$ \\
\hline Academic concentrator & & $\begin{array}{l}2.663^{* * * *} \\
(.615)\end{array}$ \\
\hline Highest math course & & $\begin{array}{l}1.321^{* * * *} \\
(.062)\end{array}$ \\
\hline
\end{tabular}


TABLE 3 (Continued)

\begin{tabular}{lcc}
\hline Variables & Model 1 & Model 2 \\
\hline Constant & $4.500 * * *$ & $.002 * * *$ \\
& $(.405)$ & $(.001)$ \\
Observations & 10,620 & 10,620 \\
Log likelihood & $-942,934$ & $-703,220$ \\
McFadden's adjusted $R^{2}$ & .029 & .276 \\
$C g$ goodness-of-fit, $g=10$ [p-value] & $35.985[<.001]$ & $26.507[.001]$ \\
\hline
\end{tabular}

NOTE.--Reported sample sizes are rounded to the nearest 10 in accordance with NCES restricted data license. Standard errors in parentheses. Demographic controls not shown. All fit statistics from stacked data.

$* p<.05$ (two-tailed tests).

$* * p<.01$.

$* * * *<.001$

between religious services and enrollment, but this shifted to include suburban students when using ELS data (with urban students having the smallest association). Overall, the way that some socioeconomic and social community factors predicted enrollment appeared to be equally or more salient for suburban students in the 2000s, whereas they were most relevant for rural students in the 1990s.

College degree attainment.-Table 4 shows how the same set of variables predicted college degree completion. The first model shows that suburban and urban students were more likely than rural students to attain a bachelor's degree or higher, confirming the differences revealed descriptively in table 1 even with controls for race, gender, and region. Specifically, suburban students had odds of attaining a bachelor's degree that were twice those of rural students.

Similar to the results for enrollment, the rural-nonrural differences in degree attainment were different when the additional variables were introduced to the model, although in this case associations did not completely disappear. Nonrural students still exhibited a statistically significant advantage in bachelor's degree attainment over rural students even in the model adjusting for all other factors, including family resources, community social resources, and academic background.

Finally, many of the typically significant predictors of degree attainment (parental educational attainment, family income, parental expectations, academic preparation) were positively associated with degree attainment as expected (table 4). In addition, the extent to which a student attended religious services (a component of social community resources) was also predictive of BA attainment or higher. The predictive factors in our final model are very similar to those produced by Byun et al. (2012) using NELS data, indicating that these predictors of degree attainment remained stable over time (results of statistical 


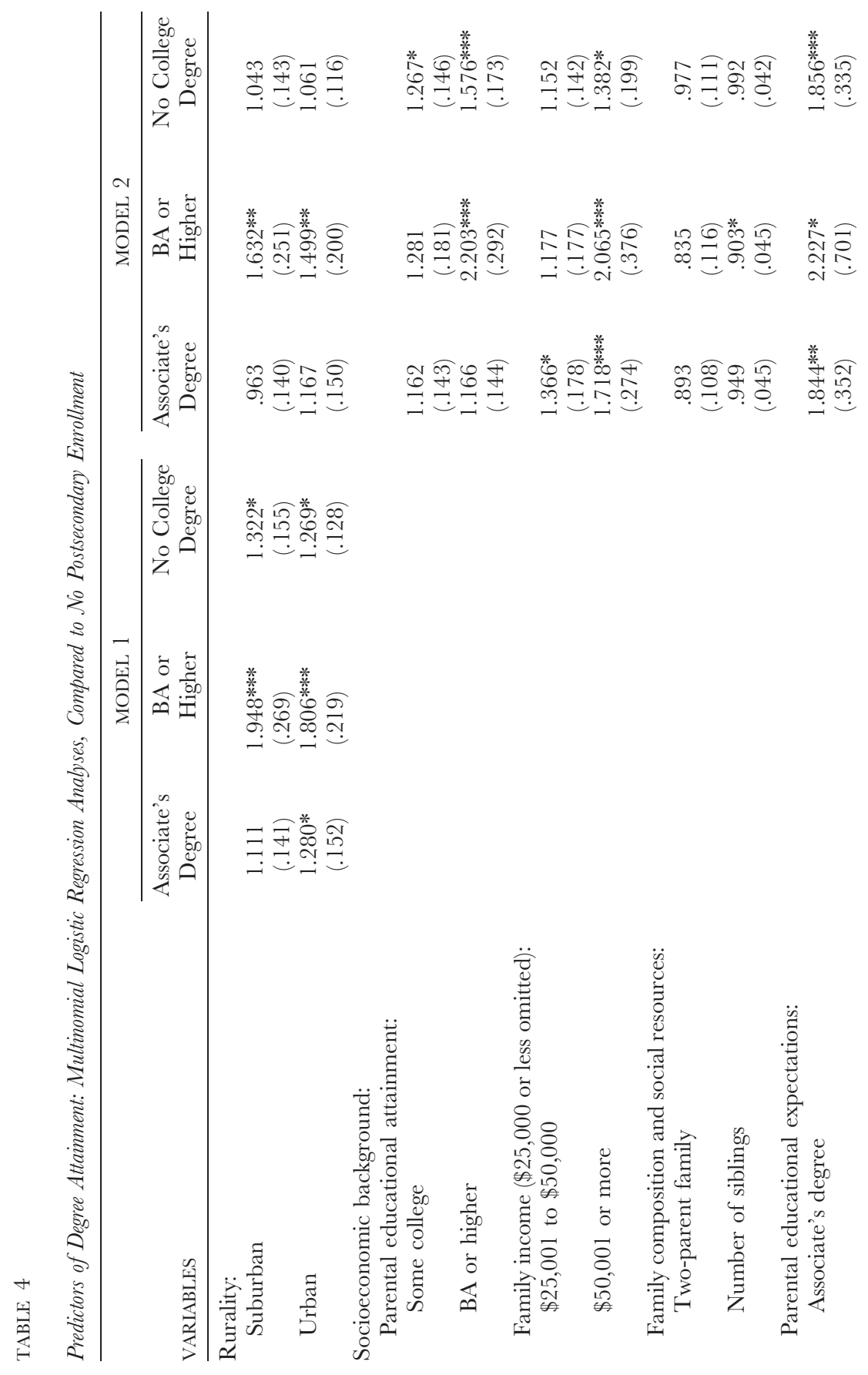




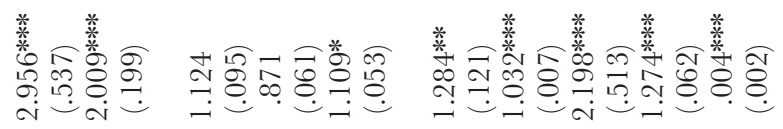

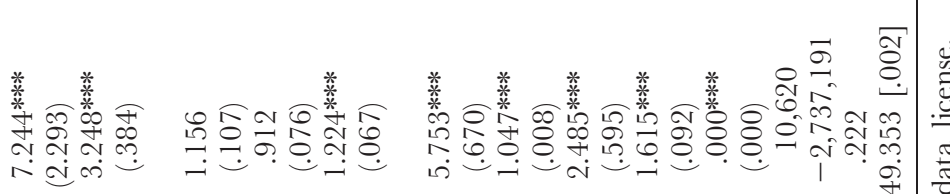

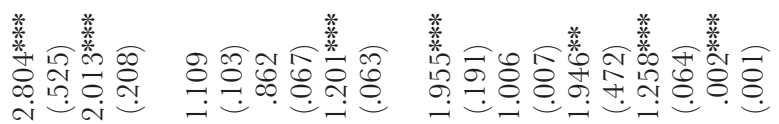

: $\quad \begin{array}{ll}0 \\ 0\end{array}$

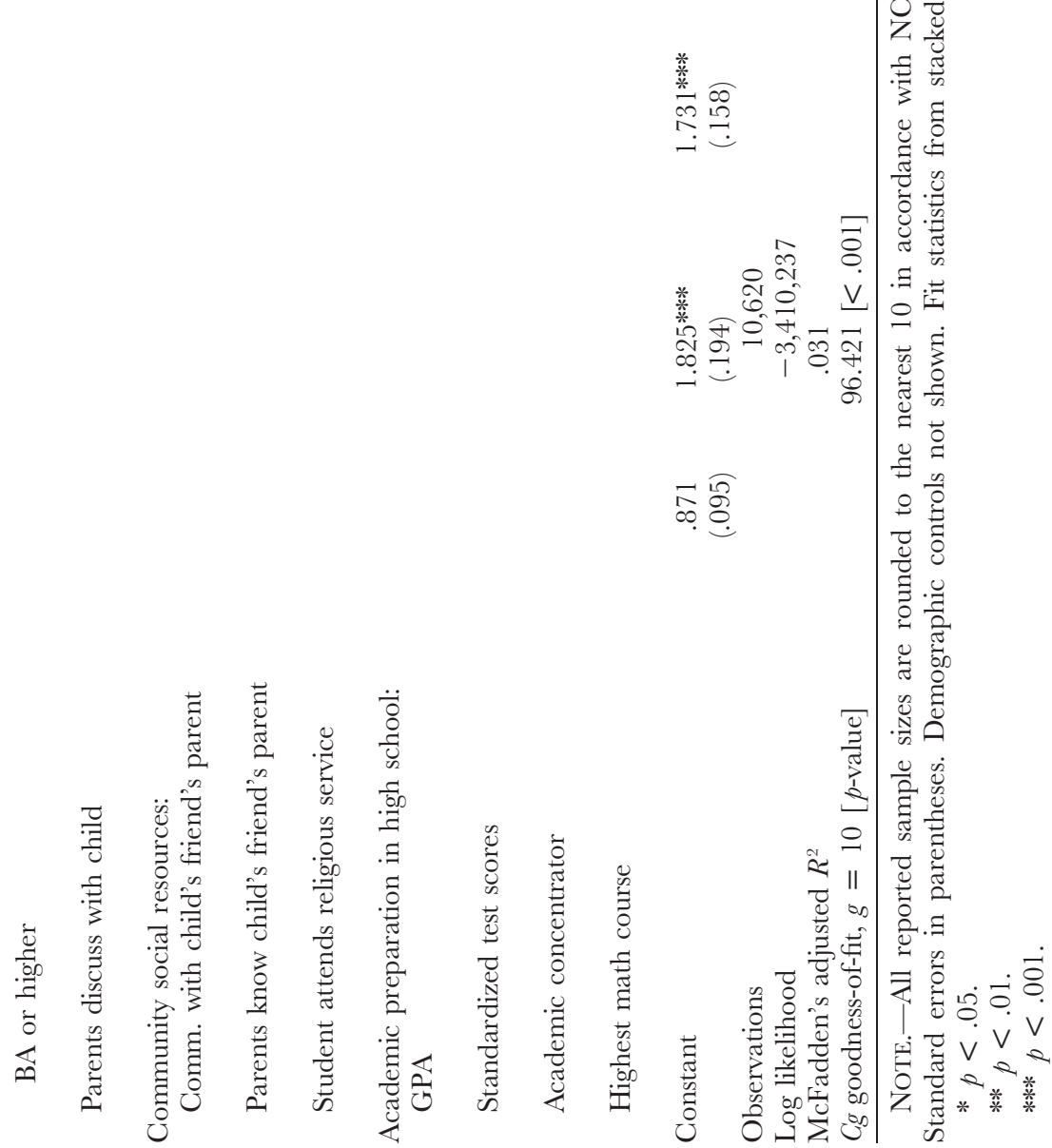


comparison between NELS and ELS regression coefficients available upon request; see also footnote 6).

We calculated predicted probabilities for degree attainment separately for rural, urban, and suburban students to aid interpretation of these results. These probabilities were created from model 2 in table 4 , and therefore adjust for all of the variables included in that model. Figure 1 shows the predicted probability of each degree outcome for a student who is average in their geographic cohort (i.e., all values set at within group means). Bars are only shown for categories and groups where there were statistically significant differences when compared to the probabilities for rural students.

Noticeably, suburban and urban students had greater probabilities of attaining a BA than rural students, but they had lower probabilities of attaining a certificate or associate's degree. In fact, the highest probability for any outcome for suburban and urban students is a bachelor's degree or higher. For rural students, the highest probability is for attaining a sub-baccalaureate credential. Additionally, rural students had slightly higher probabilities than suburban students of not attending college at all. ${ }^{9}$

When the regression model for degree completion was run separately for rural, suburban, and urban students, the largest effect sizes sometimes occurred

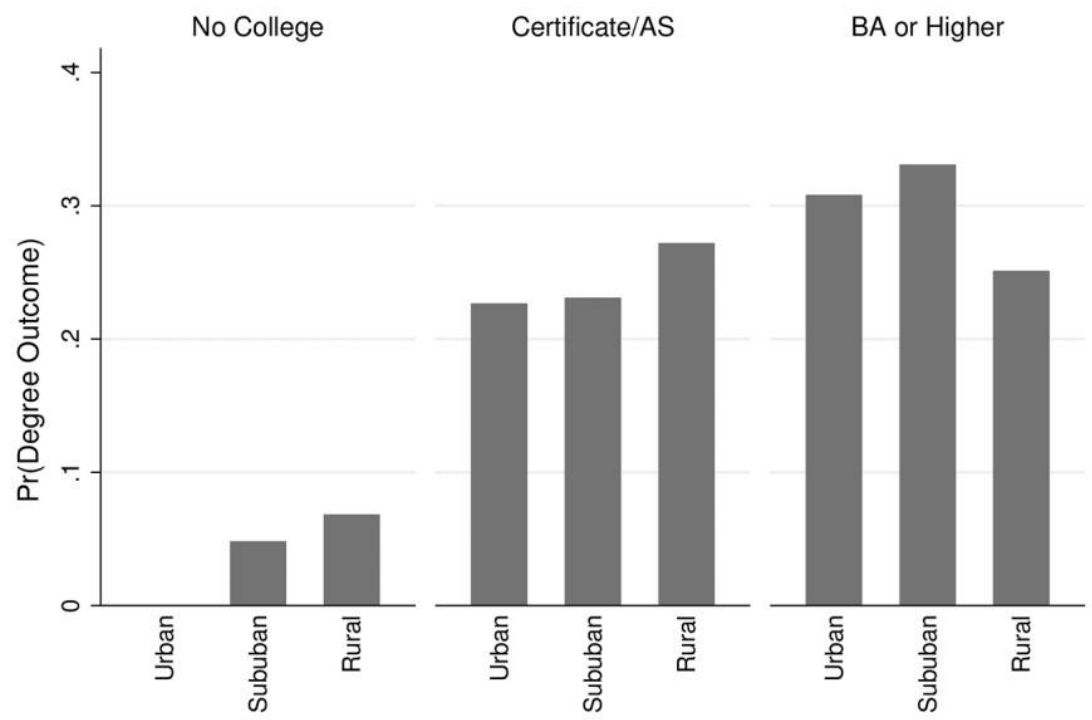

Graphs by outcome category, only for significant differences between the rural group and others

FIG. 1.-Predicted probabilities of college outcomes, by rurality/urbanicity 
for the suburban subsample, similar to results for enrollment. ${ }^{10}$ Parental educational attainment, for example, is most related to bachelor's degree attainment for suburban students compared to urban and rural students. Counter to this trend, family income was most associated with degree attainment for rural students, with weaker associations for suburban and urban students. Academic preparation had the strongest association with bachelor's degree attainment for rural students, though still predictive for suburban and urban students as well.

Given that Byun et al. (2012) specifically highlighted the role of social community resources as a positive influence for rural students in their degree attainment (and specifically the relationship between religious service attendance and degree attainment), it is worth noting that in our replication, attendance at religious services was marginally related to attainment for rural students. However, it was more strongly associated with attainment for suburban students, which is different from results using NELS data from the 1990s.

\section{Discussion}

\section{An Updated Look at Enrollment and Degree Attainment}

Our results show that rural high school seniors from 2004 lagged behind their nonrural peers in both college enrollment and degree completion. Our study complements earlier findings on the importance of socioeconomic status for rural students (Koricich et al. 2018) by showing that when adjusted for socioeconomic differences, enrollment differences diminish. Specifically, rural students have lower levels of parental educational attainment and family income than nonrural students. These factors are highly predictive of enrollment and are therefore likely a large part of the explanation of rural-nonrural gaps in postsecondary pathways. Although controlling for factors like socioeconomic background and other salient variables helps to diminish the gap in rural students' lower rates of completion compared to their nonrural peers, significant gaps remain between rural and nonrural students. Socioeconomic factors, family and community resources, and academic background do not capture the full extent of why rural students experience lower degree completion rates in comparison to nonrural students.

\section{Changes in Enrollment and Degree Attainment over Time}

Consistent with other national reports of increases in college going, our results show that compared to the 1990s, a greater proportion of high school seniors enrolled in college in the 2000s. In direct response to our research questions, we 
also found that although rural students still lagged behind others, the gap in enrollment narrowed: rural students increased their college enrollment rates more than nonrural students during this time. Despite continued gaps, this finding contains some good news for students in rural areas and indicates that, in the aggregate, the changing context of rural America over the decade studied may have led to some positive educational outcomes.

Similar to enrollment, overall degree attainment increased from the 1990s to the 2000s. This increased attainment was primarily at the sub-baccalaureate level, with all groups increasing their attainment of associate degrees and certificates by about 9 percentage points. While the increase over time at this level was similar across geography, when adjusted by covariates rural students had a higher probability of attaining a less-than-4-year credential. This may be good news if the local rural labor market rewards such credentials with meaningful, well-paying jobs (Rios-Aguilar et al. 2018). However, the correspondingly lower probability of attaining a bachelor's degree for rural students is a concern, given that credential's greater value in the labor market.

In contrast to sub-baccalaureate attainment, there were essentially no increases overall in bachelor's degree attainment. When disaggregated by rural and nonrural groups however, there was an exception for rural students. Rural students were the only group who had a small increase over time in bachelor's degree attainment, whereas suburban students had no increase, and urban students experienced a decrease in bachelor's level attainment. Again, this relative narrowing of the rural-nonrural gap is a promising counternarrative to dominant discourses about postsecondary education and rural students (e.g., Brown and Fisher 2017; Marcus and Krupnick 2017; Pappano 2017).

Changes in academic preparation over the decade being examined are also noteworthy. There were relatively higher increases in academic preparation for rural students compared with nonrural students. This is important because regression results show that these factors remain highly correlated with college enrollment and degree attainment, and therefore could be part of the story of narrowed rural-nonrural gaps. However, given rural students' average levels of academic preparation, one would expect their completion rates to be higher relative to their nonrural peers than they actually are. Other unobserved factors are likely also salient in explaining rural-nonrural disparities. These may include adjustments to a new culture or place-related mismatches that can affect college persistence, all of which should be considered in future research.

\section{Changing Rural Contexts}

This study shows diminished enrollment and attainment gaps between rural and nonrural students from the 1990s into the 2000s. Informed by literature

24 American Journal of Education 
regarding changing contexts during this time in rural America, it is possible that geographic drivers that influenced greater enrollment and attainment ratessuch as shrinking local labor market opportunities, greater access to college and employment information, and online educational opportunities - outweighed other factors that may have deterred college going. The Great Recession, which overlapped with our study time frame, may have influenced rural students to complete shorter-term sub-baccalaureate degrees for either their cheaper costs or more immediate returns in the labor market. Evidence of changing characteristics of the population could also be partially responsible for the shrinking gaps. For example, the average parental education of rural students increased more than for nonrural students during this time (table 2), with fewer rural students categorized as potential first-generation students. This change could affect the aspirations and behaviors related to college going in rural areas that would help to close the rural-nonrural gaps.

Given the centrality of attendance at religious services in the conclusions of Byun et al. (2012), we specifically examined how this factor changed over time. Religious attendance decreased overall, and particularly for rural students, which is consistent with a larger trend toward decreased religious activity in the Unites States and to the fact that religion was becoming more narrowly defined in political terms (Putnam and Campbell 2012). Nonetheless, religious service attendance was still positively associated with enrollment and attainment in the 2000s, which is similar to results from the 1990s. A difference over time, however, is that the association between this religious aspect of social community resources and college outcomes appears to be as much or more salient for suburban students compared to rural students. One of the key positive influences for rural students, therefore, may no longer be claimed as a unique benefit to that group.

\section{Implications for Policy, Practice, and Research}

The changing economic landscape of rural communities represents a pressing and particularly vexing policy concern. Within this broader challenge, the postsecondary attendance and completion of rural, college-aged youth has profound consequences for individuals' social mobility, as well as for their communities. The stratification of college attendance and completion for rural and nonrural students, therefore, represents a pressing equity concern. Likewise, given that many rural youth express a desire to return to their home community, suppressed educational achievement may deprive rural communities of the readiest source of highly trained, highly skilled labor available to them.

As the stakes associated with the college attendance and completion of rural youth are high, our study's findings suggest the need for increased attention 
to all parts of the pathway to and through college for college students from rural communities. While gaps were diminished over time, there is still a disparity between rural and nonrural college attendance and completion. Supporting rural students naturally begins with attempts to continue to increase academic preparation. Interestingly, however, given that attainment gaps remain after adjusting for previous academics, policies or programs aimed solely at increasing academic preparation for rural students are unlikely to fully address rural-nonrural degree attainment gaps. Additional research and policy attention should focus on how students from rural communities form and then enact college-going aspirations. For example, racial diversity manifests itself in rural students' college-going considerations in important ways (Means et al. 2016). Therefore, research should also better account for the ethnical and racial diversity that is increasingly present in the group of rural (potential) students, and investigate policy implications that may differ for rural students from various racial and ethnic backgrounds.

Furthermore, interventions of policy and practice that focus on increasing available support to those rural students who make it to postsecondary education are also needed. Recall that factors in this study were largely able to explain gaps in enrollment but not similarly so for degree attainment. Our study suggests the importance not just of increasing the size of the pipeline from rural communities to college, but also plugging the holes therein to ensure that more rural students who make it to college also make it through college. Increased research attention to the experience of rural students on college campuses would support such interventions. A better understanding of how factors including institutional match, place-boundedness, and/or home community resources impact students' college experiences, and eventual degree attainment, are needed.

As the number of rural youth pursuing postsecondary education increases, further attention should also be paid to the out-migration of the college educated, which has occurred in many rural areas (Carr and Kafelas 2010). Of all the rural students that go to college, only half of them return to their rural community (Gibbs 1995). Interventions of policy and practice that provide rural students an opportunity to make a positive difference in their home community by using their college education and including an economically viable path for returning home could help reverse the outmigration of youth from rural areas.

Additionally, research on all of these topics should be done with multiple definitions of rurality. Although we were careful in this study to match the definitions used in the NELS dataset for comparison, the NCES changed the way they defined rurality in ELS, and again with their newest data set, the High School Longitudinal Study. More broadly, rurality does not have one definition, and multiple ways of conceptualizing and defining rural students should be used. As noted by Isserman (2005): "Much can be gained by using these better rural 
definitions to replicate important research to see whether key findings hold true and to review eligibility requirements and funding procedures to determine whether government programs are reaching the rural people and places they are intended to serve" (465). How might findings related to college enrollment and degree attainment differ under a variety of definitions? Such research would be important in understanding which results are most robust and therefore the most obvious to address through policy and practice.

Methodologically, all varieties of research are needed to generate a thorough picture of rural college access and success, in order to inform public discourse. More qualitative studies are needed to understand factors such as the role of religious attendance, the role of place attachment, and the meaning students give to college and rurality on a personal level. Quantitatively, studies with other data sets are needed to confirm or challenge findings such as ours. The primarily correlational existing body of literature should be expanded to include causal and quasicausal studies (e.g., propensity score matching) of the effects of specific interventions on the college enrollment and completion of rural students. For example, exploring how various forms of financial aid impact rural students would be useful given our finding that family income is predictive of rural student degree attainment specifically. To support the variety of methodological approaches needed, there are several conceptual frameworks that may be useful. For example, models of college choice and success can be utilized, or perhaps adapted, for rural youth (e.g., Perna 2006; Perna and Thomas 2008). Critical perspectives on rurality may also be utilized for extending qualitative work (e.g., Thomas et al. 2011).

Research using these same data can also be extended in meaningful ways. As discussed, the recession may have influenced students in our data in ways that limit the comparability with NELS data. Specifically, most of the ELS students graduated in 2004 before the recession began. For those who immediately enrolled in college, the recession would not have impacted their enrollment but may have influenced their completion. In contrast, students who delayed their college enrollment by a few years would have been making a different kind of decision, with different influences, given the onset of the recession. Future research exploring the heterogeneity that results from different influences given the timing of college enrollment choices in relation to the recession would also be interesting and useful.

Overall, this research shows positive and negative findings for rural populations. Over the decade studied, gaps in educational outcomes with nonrural populations were narrowed. However, gaps remain, as do several challenges unique to the college trajectories of rural students. Continued research will be important for understanding the nuances of educational pathways for these students, as their rural contexts continue to change economically, socially, and demographically into the future. 
Narrowed Gaps and Persistent Challenges

\section{Notes}

1. Details of our operational definitions of these variables can be found in the supplementary table $\mathrm{S} 1$ (available in the online appendix).

2. For suburban students, getting a BA or higher was significant under MI in the analysis of degree completion, although only marginally so under listwise deletion.

3. Thank you to Soo-young Byun, who generously provided us with the standard errors from his regression analyses for comparison with our results, which were not published in the original AERf article.

4. The differences for the "number of siblings" variable between our study and the study we are replicating are much larger than expected (table 2). This deserves further investigation, but we suspect a coding inconsistency between our study and the previous study, given that national trends in the number of children per family align closely with our findings.

5. We present only the final model here, rather than all intermediate blocked models used by Byun et al. Full results with all blocks of variables can be found in the online supplement.

6. This lack of significant differences in regression coefficients over time was confirmed by pooling NELS and ELS data and rerunning all regression analyses, while including an interaction term between the cohort (NELS vs. ELS) and the independent variables of interest.

7. See supplementary table S2 (available in the online appendix).

8. We use the term "effect size" in the general sense to refer to the size of the regression coefficient, but do not imply causality by using this term, which this study's methods are not capable of supporting.

9. There were no differences in predicted probabilities between rural and urban students for the No College Degree category, which is why it is not shown in Figure 1.

10. See supplementary table S3 (available in the online appendix).

\section{References}

Allison, Paul D. 1995. "The Impact of Random Predictors on Comparisons of Coefficients Between Models: Comment on Clogg, Petkova, and Haritou." American Fournal of Sociology 100 (May): 1294-1305.

Allison, Paul D. 2002. Missing Data. Thousand Oaks, CA: SAGE.

Barcus, Holly R., and Stanley D. Brunn. 2009. "Towards a Typology of Mobility and Place Attachment in Rural America." Journal of Appalachian Studies 15 (January): 26-48.

Barcus, Holly R., and Stanley D. Brunn. 2010. "Place Elasticity: Exploring a New Conceptualization of Mobility and Place Attachment in Rural America." Geografiska Annaler: Series B. Human Geographv 92 (December): 281-95.

Brown, Sarah, and Karin Fisher. 2017. "A Dying Town." Chronicle of Higher Education, December 29. https://www.chroncle.com/interactives/public-health.

Byun, Soo-Yong, Matthew J. Irvin, and Judith L. Meece. 2015. "Rural-Nonrural Differences in College Attendance Patterns." Peabodv Fournal of Education 90 (March): 263-79. 
Byun, Soo-yong, Judith L. Meece, and Matthew J. Irvin. 2012. "Rural-Nonrural Disparities in Postsecondary Educational Attainment Revisited." American Educational Research fournal 49 (June): 412-37.

Carr, Patrick J., and Maria J. Kefalas. 2010. Hollowing Out the Middle: The Rural Brain Drain and What It Means for America. 2nd ed. Boston: Beacon.

Chenoweth, Erica, and Renee V. Galliher. 2004. "Factors Influencing College Aspirations of Rural West Virginia High School Students." Journal of Research in Rural Education 19 (October): 1-14.

Clogg, Clifford C., Eva Petkova, and Adamantios Haritou. 1995. "Statistical Methods for Comparing Regression Coefficients Between Models." American Fournal of Sociology 100 (March): 1261-93.

Crockett, Lisa J., Michael J. Shanahan, and Julia Jackson-Newsom. 2000. "Rural Youth: Ecological and Life Course Perspectives." In Adolescent Diversits in Ethnic. Economic, and Cultural Contexts. ed. R. Montemavor. G. R. Adams, and T. P. Gullotta. Thousand Oaks, CA: SAGE.

Domina, Thurston, AnneMarie Conley, and George Farkas. 2011. "The Link between Educational Expectations and Effort in the College-for-All Era." Sociology of Education 84 (April): 93-112.

Firebaugh, Glenn. 2008. Seven Rules for Social Research. Princeton, NJ: Princeton University Press.

Flora, Cornelia Butler, and Ja L. Flora. 1990. "Developing Entrepreneurial Rural Communities." Sociological Practice 8 (1): 197-207.

Gibbs, Robert M. 1995. "Going Away to College and Wider Urban Job Opportunities Take Highly Educated Youth Away from Rural Areas." Rural Development Perspectives 10 (June): 35-44.

Grusky, David B., Bruce Western, and Christopher Wimer, eds. 2011. The Great Recession. New York: Russell Sage Foundation.

Heeringa, Steven G., Brady T. West, and Patricia A. Berglund. 2010. Applied Survey Data Analysis. Boca Raton, FL: CRC.

Hillman, Nicholas W. 2016. "Geography of College Opportunity: The Case of Education Deserts." American Educational Research Fournal 53 (August): 987-1021.

Holloman, Darryl, and Amanda L. Nolen. 2008. "Recruiting Place Bound Students: The Influence of Location on the College Choice of High-School Seniors." Metropolitan Universities 19 (March): 41-53.

Howley, Caitlin W. 2006. "Remote Possibilities: Rural Children's Educational Aspirations." Peabodv Fournal of Education 81 (April): 62-80.

Ilbery, Brian, ed.. 2014. The Geography of Rural Change. New York: Routledge.

Ingels, Steven J., Daniel J. Pratt, Christopher P. Alexander, Donna M. Jewell, Erich Lauff, Tiffany L. Mattox, David Wilson, and Elise Christopher. 2014. "Education Longitudinal Study of 2002 (ELS: 2002) Third Follow-Up Data File Documentation." Washington, DC: US Department of Education, National Center for Education Statistics. nces.ed.gov/pubs2014/2014364.pdf.

Israel, Glenn D., Lionel J. Beaulieu, and Glen Hartless. 2001. "The Influence of Family and Community Social Capital on Educational Achievement." Rural Sociology 66 (March): 43-68.

Isserman, Andrew M. 2005. "In the National Interest: Defining Rural and Urban Correctly in Research and Public Policy." International Regional Science Review 28 (October): 465-99.

Johnson, Kenneth M. 2012. "Rural Demographic Change in the New Century: Slower Growth, Increased Diversity." Issue Brief No. 44. Durham: University of New Hampshire, Carsey Institute. 


\section{Narrowed Gaps and Persistent Challenges}

Koricich, Andrew, Xi Chen, and Rodney P. Hughes. 2018. "Understanding the Effects of Rurality and Socioeconomic Status on College Attendance and Institutional Choice in the United States." Review of Higher Education 41:281-305.

Lobao, Linda, and Katherine Meyer. 2001. "The Great Agricultural Transition: Crisis, Change, and Social Consequences of Twentieth Century US Farming." Annual Review of Sociology 27 (August): 103-24.

Long, Bridget Terry. 2014. "The Financial Crisis and College Enrollment: How Have Students and Their Families Responded?" In How the Financial Crisis and Great Recession Affected Higher Education, ed. Jeffrey R. Brown and Caroline M. Hoxby. Chicago: University of Chicago Press.

Long, J. Scott. 1997. Regression Models for Categorical and Limited Dependent Variables. Thousand Oaks, CA: SAGE.

Long, J. Scott, and Jeremy Freese. 2014. Regression Models for Categorical Dependent Variables Using Stata. College Station, TX: Stata.

Manly, Catherine A., and Ryan S. Wells. 2015. "Reporting the Use of Multiple Imputation for Missing Data in Higher Education Research." Research in Higher Education 56 (4): 397-409.

Manly, Catherine A., Ryan S. Wells, and S. Kommers. 2019. "Who Are Rural Students? How Definitions of Rurality Affect Research on College Completion." Research in Higher Education. doi:10.1007/s11162-019-09556-w.

Marcus, Jon, and Matt Krupnick. 2017. "The Rural Higher-Education Crisis.” Atlantic. https://www.theatlantic.com/education/archive/2017/09/the-rural-higher-education -crisis/541188/.

Marré, Alexander. 2017. "Rural Education at a Glance, 2017." Washington, DC: United States Department of Agriculture. https://www.ers.usda.gov/publications /pub-details?pubid $=83077$.

McGrath, Daniel J., Raymond R. Swisher, H. Elder Glen Jr., and Rand D. Conger. 2001. "Breaking New Ground: Diverse Routes to College in Rural America." ural Sociology 66 (October): 244-67.

Means, Darris R. 2018. Supporting the Pathways to Postsecondary Education for Rural Students: Challenges Opportunities, and Strategies for Moving Forward. Arlington, VA: National Association for College Admission Counseling. https://www.nacacnet.org/globalassets /documents/publications/research/supporting-the-pathways-to-postsecondary -education-for-rural-students.pdf.

Means, Darris R., Ashley B. Clayton, Jonathan G. Conzelmann, Patti, Baynes, and Paul D. Umbach. 2016. "Bounded Aspirations: Rural, African American High School Students and College Access." Review of Higher Education 4:543-69.

National Center for Educational Statistics. 2016. Completing College: A National View of Student Attainment Rates: Fall 2009 Cohort. Signature Report. Washington, DC: National Center for Education Statistics. https://nscresearchcenter.org/signaturereport10/.

Pappano, Laura. 2017. "Voices from Rural America on Why (or Why Not) to Go to College." New York Times, January 31. https://www.nytimes.com/2017/01/31 /education/edlife/voices-from-rural-america-on-why-or-why-not-go-to-college.html.

Perna, Laura W. 2006. "Studying College Access and Choice: A Proposed Conceptual Model." Higher Education: Handbook of Theory and Research 21:99-157.

Perna, Laura W., and Scott L. Thomas. 2008. "Theoretical Perspectives on Student Success: Understanding the Contributions of the Disciplines." ASHE Higher Education Report 34 (1): 1-87.

Petrin, Robert A., Thomas W. Farmer, Judith L. Meece, and Soo-yong Byun. 2011. "Interpersonal Competence Configurations, Attachment to Community, and 
Residential Aspirations of Rural Adolescents." Fournal of Youth and Adolescence 40 (September): 1091-105.

Petrin, Robert A., Kai A. Schafft, and Judith L. Meece. 2014. "Educational Sorting and Residential Aspirations among Rural High School Students: What Are the Contributions of Schools and Educators to Rural Brain Drain?" American Educational Research Fournal 51 (April): 294-326.

Pierson, Ashley, and Havala Hanson. 2015. Comparing Postsecondary Enrollment and Persistence among Rural and Nonrural Student in Oregon. Regional Educational Laboratory Northwest. https://files.eric.ed.gov/fulltext/ED556748.pdf.

Provasnik, Stephen, Angelina Kewal Ramani, Mary McLaughlin Coleman, Lauren Gilbertson, Will Herring, and Qingshu Xie. 2007. "Status of Education in Rural America." NCES 2007-040. Washington, DG: National Center for Education Statistics.

Putnam, Robert D., and David E. Campbell. 2012. American Grace: How Religion Divides and Unites Us. New York: Simon \& Schuster.

Rios-Aguilar, Cecilia, Ryan Wells, David Bills, and Diana D. Lopez. 2018. "The (Mis)match between Sub-Baccalaureate Credentials and Middle Skills Jobs: A Community College Spatial Research Agenda." New Directions for Institutional Research, no. 180 (Winter): 39-58.

Roscigno, Vincent J., Donald Tomaskovic-Devey, and Martha Crowley. 2006. "Education and the Inequalities of Place." Social Forces 84 (4): 2121-45.

Rosenboom, Victoria, and Kristin Blagg. 2018. "Disconnected from Higher Education," https://www.urban.org/sites/default/files/publication/96191/disconnected _from_higher_education_1.pdf.

Rubin, Donald B. 1987. Multiple Imputation for Nonresponse in Surveys. New York: Wiley.

Schafft, Kai A., and Alecia Youngblood Jackson. 2010. Rural Education for the TwentyFirst Century: Identity, Place, and Community in a Globalizing World. University Park: Pennsylvania State University Press.

Shapiro, D., A. Dundar, P. K. Wakhungu, X. Yuan, A. Nathan, and Y. Hwang. 2015. "Completing College: A National View of Student Attainment Rates-Fall 2009 Cohort." Signature Report. National Student Clearinghouse Research Center. https://nscresearchcenter.org/signaturereport10/.

Sherman, Jennifer, and Rayna Sage. 2011. "Sending Off All Your Good Treasures: Rural Schools, Brain-Drain, and Community Survival in the Wake of Economic Collapse." Fournal of Research in Rural Education 26 (November): 1-14.

Tarmann, Allison. 2003. "Fifty Years of Demographic Change in Rural America: Population Reference Bureau." https://www.prb.org/fiftyyearsofdemographicchange inruralamerica/.

Thomas, Alexander R., Brian Lowe, Gregory Fulkerson, and Polly Smith. 2011. Critical Rural Theory: Structure, Space, Culture. Lanham, MD: Lexington Books.

Turley, Ruth N. López. 2009. "College Proximity: Mapping Access to Opportunity." Sociologv of Education 82 (2): 126-46.

US Census Bureau. 2010. "2010 Urban and Rural Classification.” Washington, DC: United States Census Bureau. https://www.census.gov/geo/reference/ua/urban -rural-2010.html.

van Buuren. 2012. Flexible Imputation of Missing Data. Boca Raton, FL: CRC.

White, Ian R., Patrick Royston, and Angela M. Wood. 2011. "Multiple Imputation Using Chained Equations: Issues and Guidance for Practice." Statistics in Medicine 30 (November): 377-99. 